\section{GW23-e1060 CLINICAL OBSERVATION OF MODIFIED OIANJIN WEIJING DECOCTION ON ACUTE EXACERBATION OF CHRONIC PULMONARY HEART DISEASE}

doi:10.1136/heartjnl-2012-302920ab.2

${ }^{1} \mathrm{Jin}$ Xiaoli, ${ }^{1}$ Li Hui, ${ }^{1}$ Li Xin, ${ }^{2}$ Liu Jianbo, ${ }^{1}$ Jin Xiaoli. ${ }^{1}$ The First Affiliated Hospital of Sun Yat-Sen University; ${ }^{2}$ The First Affiliated Hospital of Guangzhou Traditional Chinese Medical University

Objectives The objective of this study was to investigate the effect of modified Qianjin Weijing decoction on acute exacerbation of chronic pulmonary heart disease, and the changes of blood soluble thrombomodulin (sTM) over time during the therapy phase.

Methods 60 patients experienced acute exacerbation of chronic pulmonary heart disease were assigned randomisation to receive either routine medicine based on the guideline only in the control group or combined with modified Qianjin Weijing decoction in the treatment group. The clinical magnificent, analysis of blood gas and sTM were recorded in all patients before and 10 days after treatment respectively.

Results The effective rate in treatment group (70.00\%) was higher than control group $(23.33 \%, \mathrm{p}<0.01)$. The sTM, partial pressure of oxygen in artery $\left(\mathrm{PaO}_{2}\right)$ and partial pressure of carbon dioxide $\left(\mathrm{PaCO}_{2}\right)$ were significantly improved in both groups after treatment compared with before treatment $(p<0.01)$.

Conclusions These results demonstrate that Modified Oianjin Weijing decoction is a good alternative for patients who suffered acute exacerbation of chronic pulmonary heart disease, protect vascular endothelial system effectively associated with routine medicine. 